\title{
SABERES, CONHECIMENTOS E AS PEDAGOGIAS DAS PERGUNTAS E DAS RESPOSTAS: atualidade de antigos conflitos
}

\author{
Silvio Sánchez Gamboa*
}

\begin{abstract}
Resumo
Este artigo indica algumas questões essenciais relacionadas com o trato que as pedagogias dão ao conhecimento e aos saberes acumulados historicamente pela humanidade. No campo da educação, as diversas maneiras de abordar essa relação podem ser agrupadas entre as "pedagogias das perguntas" e as "pedagogias das respostas". Para tanto, toma-se como ponto de partida a relação dialética entre a pergunta e a resposta como a base da produção do conhecimento e da apropriação dos saberes. Alguns exemplos tomados da trajetória histórica das teorias da educação podem ilustrar essas questões básicas da formação dos educadores.
\end{abstract}

Palavras-chave: Saberes escolares. Conhecimento. Pedagogia.

\begin{abstract}
This article points out some essential issues related to how the teaching practices deal knowledge and knowledge historically accumulated by mankind. In the field of education, the various forms of approaching this relation can be categorized into "teaching based on questions" and "teaching based on answers". To this end, the dialectic relation between questions and answers as the basis of knowledge production and knowledge appropriation is taken as the starting point. Some examples taken from the history of theories of education can illustrate the basic issues concerning teacher education.
\end{abstract}

Keywords: School Knowledge. Knowledge. Pedagogy.

\section{Introdução}

Segundo dados do MEC/INEP, a taxa de cobertura dos alunos da faixa de 7 a 14 anos atingiu $96,4 \%$ (em 2006) ${ }^{1}$, indicando uma expansão marcante nas últimas décadas. Nesse contexto, surgem os debates sobre a qualidade desse ensino e sobre as deficiências das políticas sobre a formação dos educadores. Os debates ganham profundidade quando se pretende entender os conflitos entre a expansão quantitativa e a exigência de qualidade dessa expansão. Segundo a dialética materialista, dentre as categorias explicativas do real, o movimento quantitativo - neste caso, a expansão da cobertura da escolaridade - encontra-se em relação dialética com a qualidade da educação oferecida por esse sistema. Essa relação é contraditória. A paideia destinada à formação privilegiada da aristocracia grega, ou a escola exclusiva para os herdeiros privilegiados dos modernos monopólios e/ou dos administradores das grandes fortunas acumuladas, se beneficiava de uma organização exclusiva com grandes requintes de infraestrutura e, possivelmente, com o trabalho de excelentes escravos-pedagogos. Já a escola pública, para todos, sofre insuperáveis carências, embora persiga maior performance nos indicadores estatísticos, com a concentração de alunos em escolas que funcionam em vários períodos em salas superlotadas, sem a melhoria das instalações e dos recursos orçamentários. Entretanto, a maior carência se expressa na qualidade do ensino e nas condições de formação e de trabalho dos educadores.

Dentre tantas questões relativas à qualidade, considero que no quadro das políticas públicas ganha destaque a recente definição das Diretrizes Curriculares do Curso de Pedagogia, aprovadas depois de um longo debate (Resolução n.1, de 15 de maio de 2006, do Conselho Nacional de Educação). No contexto dessas diretrizes, pretendo dar destaque a algumas questões essenciais, apontadas nos documentos e relativas à formação teórica sólida, com base no conhecimento científico e na pesquisa consolidada. Essa formação diz respeito ao trato com os saberes acumulados, a produção de novos conhecimentos e a sua relação com alguns modelos pedagógicos, particularmente aqueles que abordam a relação básica da geração e socialização do conhecimento: a articulação entre perguntas e respostas.

Antes de tratar dessas questões essenciais, vejamos algumas ponderações dessas diretrizes, as quais, de acordo com a declaração das entidades nacionais da área da educação, são consideradas como um avanço histórico, já que:

a) Definem de maneira inequívoca que o curso de
Pedagogia, enquanto uma licenciatura, constitui-se
no lócus privilegiado, ainda que não exclusivo, para
a formação de professores para exercer funções

\footnotetext{
“Professor da Universidade Estadual de Campinas. E-mail: gamboa@unicamp.br

${ }_{1}$ Dados disponíveis em: www.edudatabrasil.inep.gov.br. Acesso em: 17/01/2009.
} 
de magistério na Educação Infantil e nos anos iniciais do Ensino Fundamental.

b) Definem que essa formação para o exercício do magistério deve articular-se à formação para a produção do conhecimento em educação e para a gestão educacional, na perspectiva da gestão democrática. Rompe-se, dessa forma, com aqueles modelos fragmentados e aligeirados de formação dos profissionais da educação, fragilizados em torno de habilitações específicas e que dicotomizam a formação do bacharel e do licenciado.

c) Reconhecem e consolidam a produção teórica dos últimos vinte anos no campo da formação de professores, que afirmam a urgência e apontam caminhos para o desenvolvimento de processos formativos que assegurem uma sólida formação teórica, interdisciplinar e que se sustente no trabalho coletivo.

d) Consolidam a experiência histórica construída, principalmente ao longo dos últimos vinte anos, nos Cursos de Pedagogia das Instituições Públicas de Ensino Superior, que em sua maioria desenvolvem processos formativos que articulam, na formação de professores para a Educação Infantil e anos iniciais do Ensino Fundamental, a compreensão da educação e da escola em sua multidimensionalidade, na medida em que envolvem o estudo da escola e dos sistemas de ensino, sua organização, estrutura e funcionamento e a formação básica inicial para a pesquisa em educação. (ANPED, 2006, p. 1362, grifos meus).

Entretanto, as diretrizes também têm pontos polêmicos, relacionados com a concepção de prática de ensino, com a abundância de explicitações secundárias e com a ausência de um maior aprofundamento da conceitualizações essenciais.

Segundo Kuenzer e Rodrigues (2006), a definição da prática da docência como base corre o risco de ser "uma expressão da epistemologia da prática", decorrendo daí o desafio da sua articulação com a teoria, segundo o princípio educativo de Gramsci, retomado assim por Scheibe (2007):

O desafio é estabelecer uma formação teórica sólida, com base no conhecimento científico e na pesquisa consolidada, e não ceder à incorporação da racionalidade técnica ou do praticismo pedagógico predominante na epistemologia da reforma educacional oficial, na qual se vincula o conhecimento formativo a uma prática imediatista. (p. 60).

Em sentido semelhante, Saviani (2007) pondera que os textos do parecer e da resolução estão impregnados do espírito dos chamados novos paradigmas que vêm prevalecendo na cultura contemporânea.

O resultado nos coloca diante do seguinte paradoxo: as novas diretrizes curriculares nacionais do Curso de Pedagogia são, ao mesmo tempo, extremamente restritas e demasiadamente extensivas: muito restritas no essencial e assaz excessivas no acessório. São restritas no que se refere ao essencial, isto é, àquilo que configura a pedagogia como um campo teórico-prático dotado de um acúmulo de conhecimentos e experiências resultantes de séculos de história. Mas são extensivas no acessório, isto é, se dilatam em múltiplas e reiterativas referências à linguagem hoje em evidência, impregnada de expressões como conhecimento ambiental-ecológico; pluralidade de visões de mundo; interdisciplinaridade, contextualização, democratização; ética e sensibilidade afetiva e estética; exclusões sociais, étnico-raciais, econômicas, culturais, religiosas, políticas; diversidade; diferenças; gêneros; faixas geracionais; escolhas sexuais, como se evidencia nos termos da Resolução antes citados. (p. 127).

Com relação aos desafios de uma sólida formação teórica, que supere os riscos dos paradigmas da prática, Saviani (2007) entende que a solução está na compreensão das questões essenciais da pedagogia, já que estas articulam basicamente a teoria com a prática.

Em sua trajetória multissecular, a característica mais saliente da pedagogia pode ser identificada na relação teoria-prática. Entendida como "teoria da educação" evidencia-se que ela é uma teoria da prática: a teoria da prática educativa. Não podemos perder de vista, porém, que se toda pedagogia é teoria da educação, nem toda teoria da educação é pedagogia. Na verdade o conceito de pedagogia se reporta a uma teoria que se estrutura a partir e em função da prática educativa. A pedagogia, como teoria da educação, busca equacionar, de alguma maneira, o problema da relação educadoreducando, de modo geral, ou, no caso específico da escola, a relação professor-aluno, orientando o processo de ensino e aprendizagem. (p. 102).

A relação central entre teoria e prática diferencia as diversas concepções de educação, que podem ser agrupadas em duas grandes tendências: a primeira dá prioridade à teoria sobre a prática; e a segunda, inversamente, subordina a teoria à prática ou, no limite, dissolve a teoria na prática. Diversas correntes se situam nessas duas tendências. No primeiro grupo situam-se as pedagogias tradicionais, que centralizam a prática pedagógica no professor e sua preocupação nas "teorias do ensino", cujo problema fundamental se expressa na pergunta: "Como ensinar?". No segundo grupo situam-se as diferentes modalidades da pedagogia nova, que centralizam a prática no aluno e dão ênfase às "teorias da aprendizagem", cujo problema fundamental se traduz pela pergunta "Como aprender?", o que levou à generalização do lema "aprender a aprender".

O contraponto entre as duas tendências pedagógicas, recorrente da presença da oposição entre teoria e prática na educação, se manifesta também como contraposição entre professor e aluno e entre ensino e aprendizagem. Esses contrapontos se des- 
dobram em diversas tendências que, no percurso do século $X X$, disputam a hegemonia do campo da educação:

Pedagogia conservadora versus pedagogia progressista, pedagogia católica (espiritualista) versus pedagogia leiga (materialista), pedagogia autoritária versus pedagogia da autonomia, pedagogia repressiva versus pedagogia libertadora, pedagogia passiva versus pedagogia ativa, pedagogia da essência versus pedagogia da existência, pedagogia bancária versus pedagogia dialógica, pedagogia teórica versus pedagogia prática, pedagogias do ensino versus pedagogias da aprendizagem. E, dominando todo o panorama e, em certo sentido, englobando as demais oposições, pedagogia tradicional versus pedagogia nova. (SAVIANI, 2007, p.110).

A superação desses contrapontos está na compreensão dialética da unidade de contrários. A teoria e a prática têm especificidades e diferenças, mas são aspectos inseparáveis da ação humana, já que tanto a prática se faz em relação à teoria, como a teoria em relação à prática.

A existência de uma ou outra depende da relação mútua entre elas. É na relação com a prática que se inaugura a existência de uma teoria; não pode existir uma teoria solta. Se existe, é como teoria de uma prática. A prática existe, logicamente, como prática de uma dada teoria. É a própria relação entre elas que possibilita a existência. (SÁNCHEZ GAMBOA, 2007, p. 47).

A pedagogia como teoria da educação se justifica, se constitui e se desenvolve em função da prática, que opera também como fundamento, finalidade e critério de verdade; por sua vez, os problemas que a prática da educação apresenta somente podem ser esclarecidos e compreendidos pela teoria, que opera também como critério de coerência e eficácia. Sem a teoria, a prática perde seu sentido e a sua dimensão de ação humana.

Na oportunidade da elaboração das Diretrizes Curriculares do Curso de Pedagogia, essa concepção unificadora esteve ausente, ou minimizada, dentre outras questões essenciais tais como: a maior explicitação sobre o campo teórico-prático da educação e a formação básica para a pesquisa e para a produção do conhecimento em educação. Alguns princípios são sucintamente enunciados. Em contrapartida, as formas, situações e modalidades da prática pedagógica são exageradamente explicitadas. Nesse sentido, os documentos separam os elementos teóricos já reduzidos, das formas da prática, amplamente anunciadas. Tal separação indica que no consenso possível, na elaboração e aprovação dos documentos, predominaram as concepções que propiciam dualismos, dispersões e confusões na relação básica do campo teórico-prático da educação ou, como denuncia Scheibe (2007) no texto acima citado, predomina a visão dos novos pragmatismos.

$\mathrm{Na}$ oportunidade da retomada das questões essenciais, minimizadas nos documentos das diretrizes, me proponho a apontar outros elementos que poderão contribuir na discussão sobre a formação dos educadores. Como explicitei acima, esses elementos dizem respeito a um dos pontos-chave anunciados nos documentos: o trato com o conhecimento e os saberes acumulados pela humanidade e seus desdobramentos nas concepções pedagógicas. Pautado pela compreensão da unidade dialética entre contrários, pretendo explicitar os contrapontos entre saberes e conhecimento e entre as pedagogias das perguntas e das respostas, retomando alguns antigos conflitos trazidos pela história do pensamento pedagógico, daí a justificativa para o subtítulo: atualidade de antigos conflitos.

Para apresentar esses apontamentos, organizo minha exposição em três tópicos: a) a relação dialética entre pergunta e resposta como base da produção do conhecimento; b) os conflitos das pedagogias; e c) algumas experiências de superação na trajetória da história das teorias da educação. Finalmente, aponto alguns desdobramentos para a formação do educador no contexto dos conflitos da expansão quantitativa e os desafios da qualidade da educação.

\section{A unidade entre pergunta e resposta}

Segundo Bachelar (1989), o conhecimento resulta da relação básica entre as perguntas e as respostas: "Para o espírito científico qualquer conhecimento é uma resposta a uma pergunta. Se não há pergunta não pode existir conhecimento científico. Nada se dá; tudo se constrói." (1989, p. 189).

A relação entre perguntas e respostas pode ser entendida como uma relação dialética de unidade de contrários. Pela unidade de contrários existe um estabelecimento recíproco, os aspectos, e não podem existir uns sem os outros. Assim, "a identidade dos contrários é um momento da contradição, que é tão necessária, quanto a sua diferença." (CHEPTULIN, 1982, p. 288).

O processo lógico, que compreende os movimentos contrários entre a gestação das perguntas e a elaboração das respostas sobre um determinado objeto ou fenômeno, produz o conhecimento sobre esse objeto. O conhecimento é o resultado da unidade dialética entre as perguntas e respostas sobre esse mesmo objeto, sob condições materiais, sociais e históricas específicas. Daí o caráter temporário e determinado desse resultado.

O conhecimento como resultado da dinâmica contradição entre perguntas e respostas situa-se no 
mundo concreto da necessidade humana, a qual se manifesta nas relações concretas, situadas no espaço e no tempo dos homens com a natureza, com os outros homens e consigo mesmo. Tais relações sempre estiveram cercadas de mistérios. Perante eles foram se qualificando indagações, suspeitas, dúvidas, questões e perguntas. Uma vez conseguida a fase qualificada da pergunta, a humanidade vem procurando e consolidando respostas, seja mediante a utilização da razão mítica ou das tradições religiosas (mitus), ou de outras formas de elaboração de respostas. O sistema de respostas adquiriu uma lógica própria nas mitologias ou nas religiões, que remontam aos tempos passados longínquos (in illo tempore), às origens dos seres humanos e à explicação e à justificativa que eles elaboraram sobre a natureza e sobre o seu mundo das suas necessidades concretas, relacionadas com a sua sobrevivência e evolução histórica.

$\mathrm{Na}$ medida em que os mitos e as religiões foram se esgotando na sua capacidade heurística de oferecerem respostas para as necessidades humanas, surgem outras formas, resultado da ação demolidora e inevitável da dúvida, que, como elemento dinamizador do conhecimento, vem gerando novas suspeitas, indagações, questões e qualificando novas perguntas. Dessa forma, a humanidade também busca outras formas de produção das respostas. As respostas passam a ser construídas a partir do mundo prático, do mundo da experiência e da vida cotidiana. A essa forma de elaborar respostas com base na opinião e no senso comum, os primeiros filósofos gregos denominaram de doxa ou saber opinativo.

Entretanto, tal forma se esgota e torna-se insuficiente para oferecer respostas às necessidades e aos novos problemas da humanidade. Perante a crise de credibilidade, e dinamizadas pela dúvida, surgem também, com os primeiros filósofos como Tales de Mileto (640-548, a C.), novas formas de se produzirem as respostas. Formas que se diferenciam daquelas oferecidas pelas tradições, a razão mítica e as religiões (mitus), e pelo senso comum (doxa ou saber opinativo). A essas novas formas deu-se o nome genérico de episteme (o saber metodicamente organizado e teoricamente fundamentado). A episteme afeta radicalmente a forma de elaborar as perguntas e as respostas.

Com relação às perguntas, essas ganham a possibilidade de serem respondidas na medida em que explicitam a sua relação direta com o mundo da necessidade e com o entendimento, as expectativas e as condições do sujeito que indaga. Essa exigência de concreticidade se explicita, como veremos posteriormente, no exemplo de Sócrates, quando a pergunta é qualificada através de novas indagações para revelar a sua origem e as situações e suas necessidades específicas, as curiosidades, as preocu- pações, as crises, as suspeitas que a motivaram. De igual forma, a pergunta é qualificada com indagações e dúvidas que pretendem conferir se as respostas, suposições, opiniões, mitos, tradições e saberes já conhecidos oferecem algum tipo de resposta satisfatória à pergunta formulada. Como podemos verificar, a pergunta não é respondida imediatamente, ela precisa ser qualificada com novas indagações. A essa fase crítica, prévia à elaboração da resposta, modernamente a epistemologia cunhou o termo de problematização ou problematizar o problema, indagar sobre suas origens concretas (situação problema), explicitando tanto a necessidade, as condições, as situações percebidas pelos sujeitos, como as expectativas, suspeitas e dúvidas sobre os saberes já postos como possíveis respostas. Em síntese, deve-se explicitar a relação entre o indagador sujeito e o objeto-problema que é indagado (quem pergunta sobre o quê), assim como as condições que determinam essa relação (situação-problema).

A episteme, além de explicitar as condições concretas da origem da pergunta, também exige a explicitação da elaboração da resposta. A elucidação do caminho entre a pergunta e a resposta foi chamada de método (methodos). A episteme tem como base o método geométrico, que serve de fundamento para o moderno método científico quando afirma que o "caminho de ida traz o caminho de volta", o caminho da descoberta exige o caminho da justificativa. A exigência da prova, da verificação do retorno ao ponto de partida cria uma dialética entre a pergunta (ponto de partida) e a resposta (ponto de chegada). A sua prova está na volta à pergunta, conferindo a sua correspondência lógica e gerando novas perguntas, na medida em que as suspeitas e as dúvidas surgem perante os próprios limites das respostas. Nesse sentido, a "episteme" levanta dúvidas e questões para suas próprias respostas. $\mathrm{O}$ mesmo não acontece com o mito e o senso comum. Estes não pretendem falsear suas respostas; pelo contrário, progridem à medida que ganham adeptos e se transformam em dogmas.

Uma vez obtidas as respostas, estas ganham forma autônoma e podem ser separadas e deslocadas no espaço e no tempo das perguntas que lhe deram origem e dos processos que permitiram a sua elaboração. Tais respostas são congeladas, afixadas, sistematizadas, organizadas na forma de informações padronizadas e selecionadas para serem divulgadas, transmitidas e consumidas em forma de dados, informações, saberes, teorias, esquemas, fórmulas, receitas, resumos, livros, publicações, bibliotecas e redes de informação.

Nessa fase, o conhecimento é congelado, deslocado das condições concretas da sua produção e separado da relação dinâmica entre pergunta - resposta, transformando-se num saber (resposta já 
dada, já dita) pronto para ser apropriado, formatado, sistematizado, utilizado e acumulado pela humanidade. O conhecimento, como resposta obtida, transformado em saberes, perde sua dinâmica quando o conflito entre pergunta e resposta é superado na síntese da resposta. Como resultado possível nas condições específicas do processo da sua elaboração, esse conhecimento poderá ser reconhecido e divulgado como saber significativo a ser acumulado pela humanidade. Para seu desenvolvimento posterior precisa resgatar a sua dinâmica, através da dúvida. As respostas já dadas e reconhecidas deverão ser confrontadas com as novas condições das necessidades e dos problemas que lhe deram origem. Nesse sentido, a dúvida transforma-se na locomotiva da história do conhecimento.

A dúvida transforma a resposta obtida (síntese), afirmada como saber constituído na sua negação, na sua forma contrária (antítese), numa nova pergunta que irá exigir a produção de novas respostas.

Segundo esse entendimento da relação dialética entre perguntas e respostas, tidas como polos opostos da mesma dinâmica, é necessário explicitar as diferenças entre conhecimento e saberes. Eles se colocam de forma oposta e contraditória, no mesmo processo. Enquanto o conhecimento se refere à parte dinâmica, ao processo de qualificar perguntas e produzir as respostas novas, os saberes se referem ao produto, à resposta elaborada, fechada, empacotada, sistematizada para ser distribuída, divulgada e consumida. Nesse sentido, conhecimento e saberes, embora contrários na funcionalidade, estão juntos na dinâmica dialética entre perguntas e respostas sobre um determinado fenômeno ou objeto.

No contexto da organização escolar, os conhecimentos elaborados e acumulados pela humanidade são apropriados na forma de saberes e transformados em conteúdos didáticos e matérias curriculares. Nesse sentido, a denominação de saberes escolares é a mais apropriada. A característica dos saberes é a de se apresentarem como respostas, separadas das suas perguntas originárias, como produtos separados dos processos de produção. Nesse sentido, os saberes são respostas ou "produtos" que não exigem sua relação imediata com as perguntas e os processos originários da sua elaboração. Os saberes escolares poderão, portanto, homogeneizar e padronizar diversos saberes indiscriminadamente e, sem diferenciar a sua origem, nem os processos utilizados para a sua elaboração, poderão misturar saberes (respostas já dadas) oriundos da razão mítica, da doxa ou da episteme. Daí a necessidade, no desempenho profissional dos educadores, de uma formação teórica sólida, com base no conhecimento científico e na pesquisa consolidada, para evitar esses riscos.
No contexto da transmissão dos saberes e sua institucionalização nos sistemas escolares, as pedagogias desempenham papel significativo na transmissão das respostas prontas, acumuladas nos saberes escolares e acadêmicos, mas sem considerar as perguntas que as geraram. Este é o pecado original das pedagogias: tentar transmitir respostas e saberes deslocados das perguntas e dos problemas que lhes deram origem. $O$ debate atual entre as pedagogias das perguntas e das respostas é mais uma nova tentativa de superação desse pecado original, buscando diminuir o distanciamento entre as perguntas geradoras do conhecimento e as respostas acadêmicas congeladas nos saberes escolares e amplamente divulgadas como informações ou saberes, através dos sistemas informatizados, livros e materiais didáticos e conteúdos curriculares. $\mathrm{Na}$ conjuntura atual da chamada sociedade da informação, apresenta-se uma multiplicidade de dados, registros e informações que invadem por todos os meios nossa atenção, dando-nos a sensação de termos todas as respostas possíveis. Entretanto, perante $o$ intenso bombardeiro de informações, cabe indagar: Onde estão as perguntas que geraram tantas respostas? Essas perguntas foram esquecidas $\mathrm{e}$ distanciadas das situações e dos problemas em que se originaram.

No mesmo contexto do surgimento da episteme grega, Sócrates (469-399, a. C.) já denunciava o esvaziamento das perguntas no modelo da escola aristocrática (skhole: lugar do ócio e do lazer para os privilegiados); em contrapartida, na sua escola pública da rua (ágora) aplicava a pedagogia da ironia e da maiêutica, que consistia em responder as indagações formuladas pelos seus discípulos com novas questões, com o intuito de qualificar essas questões e de levar o indagador a encontrar, ele mesmo, a resposta no mesmo lugar da pergunta. A resposta estará no mesmo contexto da pergunta e no mesmo nível das expectativas do indagador. Daí o significado da busca da verdade em si mesmo e do maior dos saberes estar no conhecimento de si mesmo.

$O$ debate entre as pedagogias das perguntas e das respostas pode ser organizado em torno das seguintes questões: Qual o sentido da relação entre pergunta e resposta? Qual o papel das pedagogias nessa relação? Na separação entre as perguntas e as respostas separam-se também as pedagogias, as que privilegiam a dinâmica das perguntas ou as que optam pela transmissão das respostas? É possível superar os conflitos entre as pedagogias das perguntas e as pedagogias das respostas?

Para desenvolver essas questões partimos do pressuposto da unidade - tanto da pergunta como da resposta, em torno de um mesmo problema ou de um mesmo objeto - o que exige diferentes atitudes dos sujeitos e um trato diferenciado da relação dia- 
lética entre pergunta e resposta, relação tida como básica em todo conhecimento, em todo saber.

\section{O conflito das pedagogias}

O conflito entre o predomínio da pergunta, do produto (saberes) e da pergunta e do processo (conhecimento) tem gerado diversas interpretações. Tomamos como exemplo algumas das mais significativas experiências na evolução da história da pedagogia que ajudam a costurar as teses do conflito entre saberes, conhecimentos e as pedagogias das perguntas e das respostas. Essas experiências, distantes no tempo, trazem elementos para articular essas teses e ver seus desdobramentos sobre as questões essenciais da educação, da formação do educador e da prática pedagógica.

Além da maiêutica de Sócrates (Séc.V a. C.), que desenvolve a pergunta qualificada como instrumento fundante do conhecimento e da verdade contra o saber mítico e a doxa que se impõem como respostas prontas, Comenio (Séc. XVI) também apresenta o conflito entre as diversas pedagogias. $\mathrm{Na}$ sua didática magna (COMENIO, 1985), ele denuncia a instrução autoritária, verbalista e vazia e que utiliza palavras cujo referente está distante, oferecendo informações obscuras e confusas sob a versão única (paráfrase) do instrutor. Opondo-se a essa prática, Comenio propõe o discurso lúdico (Schola ludus), que supõe a relação direta do sujeito com o objeto, isto é, a produção de um discurso com base na observação, na manipulação, no contato direto, na verificação sobre o objeto. Comenio trata aqui da elaboração do conhecimento. Dessa forma, confronta os saberes sobre objetos distantes, transmitidos pelo instrutor autoritário, e o conhecimento, produto da relação entre o sujeito e o objeto².

Freire (1985) denuncia o autoritarismo da prática pedagógica quando o educador trabalha apenas com repostas prontas que inculca no educando.

O educador de modo geral, já traz a resposta sem se the terem perguntado nada. (...) O autoritarismo que corta as nossas experiências educativas inibe, quando não reprime, a capacidade de perguntar. A natureza desafiadora da pergunta tende a ser considerada, na atmosfera autoritária, como provocação à autoridade. $\mathrm{E}$, mesmo quando isso não ocorra explicitamente, a experiência termina por sugerir que perguntar nem sempre é cômodo. (1985, p. 46).

Segundo Freire, o educador autoritário teme

\footnotetext{
${ }^{2}$ Comenio utiliza uma terceira opção mediadora, que consiste no uso do discurso polêmico. Esse discurso utiliza outras versões (polissemia), com a ajuda de figuras, mapas, imagens, relatos que aproximam o objeto, mas não o fazem presente, como acontece na pedagogia lúdica.
}

ser perguntado pela resposta que deve dar, pois "tem mais medo da resposta do que da pergunta". Entretanto, o fato de reprimir a pergunta no processo pedagógico é apenas um indicador da repressão maior - "a repressão do ser inteiro, à sua expressividade em relações no mundo e com o mundo". (id. ibid., p. 46).

O silêncio à pergunta, imposto em nome da ordem, significa afogar no aluno a capacidade de indagar. Nesse exemplo, Freire tende a privilegiar o processo da produção do conhecimento a partir da pergunta e entender os saberes como respostas que o professor impõe autoritariamente, com conseqüências desastrosas para a formação integral do aluno.

Saviani (1987) considera que a pedagogia tradicional estruturou o ensino no método de exposição fundado na doutrina da transmissão e assimilação de conhecimentos estabelecidos, definitivos e logicamente formalizados nas publicações científicas, nos tratados e nas bibliotecas. Já a "escola nova" tendeu a classificar esse método como pré-científico, ou até mesmo como anticientífico ou dogmático. O movimento da escola nova privilegia o processo de obtenção de conhecimentos, tomando como sequência os passos do método da pesquisa científica, que toma como base as dúvidas sobre um determinado problema, recolhe dados, formula hipóteses, explica o problema e confirma (testa a hipótese). Trata-se de uma pedagogia que pretende centrar o processo "nos interesses da criança em desenvolver procedimentos que a conduzam à posse dos conhecimentos capazes de responder às suas dúvidas". (SAVIANI, 1987, p.30).

Nesse exemplo, Saviani atribui à pedagogia tradicional a ênfase nos saberes científicos e a disseminação desses saberes sistematizados, enquanto a escola nova deprecia esses saberes e privilegia a aquisição de conhecimentos de acordo com as motivações dos alunos. Nessas duas tendências confrontam-se a pedagogia da resposta (tradicional) e a pedagogia das perguntas (escola nova).

Entendo que, segundo essa polarização, e de acordo com Saviani, a escola tradicional se afirma nos processos de ensino e na disseminação de saberes sistematizados e tidos como científicos. Já a "escola nova" acabou por dissolver a diferença entre pesquisa e ensino: "Assim fazendo, a 'Escola Nova' não se deu conta que, ao mesmo tempo, que o ensino era empobrecido, se inviabilizava também a pesquisa" (SAVIANI, 1987, p. 31). Em outro texto, Saviani (1986) afirma que ensino não é pesquisa, trazendo o argumento da teoria da curvatura da vara e ponderando as contribuições da escola tradicional perante a negação da "escola nova". Nesse texto, defende as teses: "[...] do caráter revolucionário da pedagogia da essência (pedagogia tradicional) e 
do caráter reacionário da pedagogia da existência (pedagogia nova) e do caráter científico do método tradicional e do caráter pseudocientífico dos métodos novos" (SAVIANI, 1986, p. 62). Segundo o autor, o ensino tradicional se propunha a transmitir os conhecimentos obtidos pela ciência, já compreendidos, sistematizados e incorporados ao acervo cultural da humanidade. Daí seu caráter científico. Já a pesquisa é incursão no desconhecido. E o desconhecido só se define em confronto com o conhecido. Os métodos novos que depreciam o conhecido propõem uma pseudopesquisa, já que "sem domínio do desconhecido não é possível incursionar no desconhecido". (id. ibid., p. 51). A fraqueza dos métodos novos está na falta de domínio dos saberes conhecidos, transformando a pesquisa numa brincadeira ou num faz de conta. A força do ensino tradicional está na ênfase dada aos saberes científicos, pois sem esse domínio do conhecido não é possível avançar nas pesquisas.

Na mesma trilha de Saviani, Duarte (2003) denuncia a falsa sociedade do conhecimento que, com base nas pedagogias da competência, do aprender a aprender, do construtivismo e da linha do professor reflexivo, subestima a transmissão dos saberes e as experiências acumuladas e privilegia as aprendizagens que o indivíduo realiza por si mesmo (Escola Nova). Para Duarte, as pedagogias do aprender a aprender estabelecem uma hierarquia valorativa, na qual aprender sozinho situa-se em um nível mais elevado que o da aprendizagem resultante da transmissão de conhecimentos por alguém. Assim, nas pedagogias do aprender a aprender, "é mais importante o aluno desenvolver um método de aquisição, elaboração, descoberta, construção de conhecimentos que esse aluno aprender os conhecimentos que foram descobertos por outras pessoas" (DUARTE, 2003, p.8). Com base nos postulados da Escola Nova, a aprendizagem deve ser impulsionada e dirigida pelos interesses da própria criança, visando a preparar os alunos para acompanhar a sociedade no seu acelerado processo de mudança, no qual os conhecimentos já elaborados rapidamente se tornam caducos e provisórios. Essas perspectivas criam a ilusão da facilidade do acesso ao conhecimento, da facilidade de mobilizar conhecimentos postos na prateleira dos sistemas de informação. Tal competência é mais importante que adquirir conhecimentos e dominar teorias.

$\mathrm{Na}$ "sociedade do conhecimento", todas as respostas são postas para serem consumidas, de acordo com os gostos dos fregueses. Os conhecimentos são confundidos com os saberes e diluídos indistintamente nos sistemas de informação e nas redes da internet. Apresentam-se apenas as respostas, mas as perguntas que geraram esses conhecimentos são abandonadas, esquecidas pelo pragmatismo da utilização imediata e oportunista das informações. Além da poluição de falsos conhecimentos, a internet, por exemplo, dá a sensação de oferecer respostas para todas as perguntas. Os alunos, "falsos pesquisadores", não precisam problematizar o problema, nem construir suas próprias respostas, apenas buscar as respostas que já estão prontas navegando na internet e localizando-as em algum sítio, para serem copiadas ou consumidas.

Tais ilusões de ter acesso a todas as respostas descaracterizam os processos concretos e históricos das transformações sociais, os conflitos socioeconômicos da divisão, as desigualdades de classes e descaracterizam, de igual forma, os conhecimentos e as teorias que explicam e compreendem essas relações e essas dinâmicas. Nesse sentido, "[...] a assim chamada sociedade do conhecimento é uma ideologia produzida pelo capitalismo, é um fenômeno no campo da reprodução ideológica do capitalismo". (DUARTE, 2003, p. 13).

Depois de apresentar exemplos sobre o conflito entre respostas (saberes) e perguntas (conhecimento), passo a retomar nessas mesmas experiências as propostas de superação dos conflitos entre as pedagogias das perguntas e da respostas.

\section{As experiências de superação}

Sócrates, depois de ironizar a prepotência dos saberes impostos pelos mitos e o senso comum, desenvolve a pedagogia da dúvida, da pergunta, da polêmica e do diálogo, qualificando as indagações de seus discípulos e levando-os à descoberta da verdade dentro de si. Comenio, depois de denunciar o verbalismo autoritário dos instrutores e a insuficiência dessa pedagogia repetitiva para atender os desafios da formação do homem universal e do cidadão do mundo, propõe a pedagogia lúdica que supera a falsidade do discurso autoritário, distanciado dos referentes (objetos). A superação proposta pela pedagogia lúdica inclui as mediações de aproximação dos objetos aos sujeitos da relação pedagógica. Tal relação imediata entre sujeitos e objetos, possibilitadas pelas estratégias de ensino, permite um aprendizado qualitativamente diferenciado.

A didática proposta por Comenio visa a um ensino "verdadeiro, completo, claro e sólido" a partir do encontro do homem com a natureza. O verdadeiro ensino apresenta diretamente as coisas sensíveis aos sentidos. Quando isso não é possível, pelo menos, devem se apresentar suas imagens, ou referentes mais próximos, daí a importância das ajudas audiovisuais que, no tempo de Comenio, consistia no Atlas Científico llustrado "Orbis Pictus" elaborado com a finalidade de que "junto com as palavras chegassem às crianças, se não as coisas, pelo menos as imagens das coisas (Manacorda, 1989, p. 221) ou através da dramatização "Schola Ludus", 
fazendo que as crianças encarnassem os personagens da história e da sociedade (SÁNCHEZ GAMBOA, 1992, p. 9).

A utilização de imagens, relatos e dramatizações que oferecem outras versões possibilita desenvolver um método ativo e um discurso polissêmico, intersubjetivo, entretanto distante ainda do método natural intuitivo, que se embasa no princípio baconiano da origem empírica do conhecimento ${ }^{3}$. O discurso polêmico ou polissêmico é uma mediação parcial, já que o ensino "verdadeiro, completo, claro e sólido" permite elaborar um discurso lúdico, com base no contato direto dos alunos com os objetos que são interrogados, manipulados, trabalhados, conferidos, verificados, gerando um conhecimento objetivo. Nessa relação, o discurso "científico" e lúdico nasce da relação com as coisas. Comenio, semelhantemente a Sócrates, desenvolve a pedagogia da dialógica e da polêmica, visualizando a unidade dos saberes oferecidos pelas diversas versões, com o conhecimento elaborado no contato direto com os objetos (pesquisa).

Outro exemplo de superação é trazido por Freire no seu diálogo com Faundez (FREIRE; FAUNDEZ, 1985). Depois de denunciarem o ensino tradicional por privilegiar as respostas e esquecer as perguntas, os dois educadores reafirmam que a base de todo conhecimento é a curiosidade e a pergunta, que todo saber é resposta a uma pergunta e apresentam propostas para a formação do educador. Para eles, um dos pontos de partida para a formação de um educador ou de uma educadora, numa perspectiva libertadora, democrática seria a indagação: "O que é perguntar?" (p. 46).

Nesse sentido, o problema que se coloca ao professor é de caráter prático, de ir criando com os alunos o hábito e a virtude "de perguntar e de espantar-se". A primeira coisa que aquele que ensina deveria aprender é saber perguntar e saber perguntarse. Na sua prática pedagógica o professor deveria valorizar em toda sua dimensão o que constitui as linguagens de perguntas antes de serem linguagens de respostas.

O objeto dessas perguntas, segundo os autores, deve se referir aos problemas que estimulam a sociedade e que partem da própria existência cotidiana, dos gestos, das perguntas corporais, das perguntas que o corpo faz, segundo expressão de Freire.

Preocupados em reafirmar a importância da pedagogia da curiosidade, além de insistir que a origem do conhecimento está no ato mesmo de perguntar, Freire e Faundez (1985) também destacam

\footnotetext{
3 Bacon (1561-1626), empirista inglês que influenciou as concepções filosóficas de Comenio particularmente através da obra "Instauratio magna".
}

a importância das perguntas durante o processo da elaboração das respostas, que a meu entender, não vêm imediatamente nem se encontram nos saberes prontos e acabados, impostos pelos docentes. Segundo os autores citados (1985), as perguntas também têm uma função no processo do conhecimento ${ }^{4}$.

Há perguntas que são mediadoras, perguntas sobre perguntas, às quais se deve responder. $\mathrm{O}$ importante que esta pergunta sobre a pergunta, ou estas perguntas sobre as perguntas, e sobre as respostas, esta cadeia de perguntas e respostas, enfim, esteja vinculada à realidade, ou seja, que não se rompa a cadeia. Porque estamos acostumados ao fato de que essa cadeia de perguntas e respostas, que no fundo é senão o conhecimento rompe-se, interrompe-se, não alcança a realidade. (p.49).

Enquanto a educação de respostas tende a ser generalizadora, repetidora, inibidora e "domesticadora", a educação de perguntas se apresenta como uma proposta nova, criativa e apta a estimular a capacidade humana de assombrar-se, de responder ao seu assombro e resolver seus verdadeiros problemas essenciais, existenciais (id. ibid., 1985, p. 52). Enquanto o caminho é mais fácil para a pedagogia da resposta, porque nele não se arrisca nada, a pedagogia das perguntas é uma pedagogia do risco, que está ligada à pedagogia dialética da negação do erro.

Se negarmos a negação que é o erro, essa nova negação é que dará positividade ao erro; essa passagem do erro ao não-erro é o conhecimento. [...] A força do negativo é fundamental, como dizia Hegel. A força do negativo no conhecimento é parte essencial do conhecimento, chama-se a isso erro, risco, curiosidade, pergunta, etc. (FREIRE; FAUNDEZ, 1985, p. 52).

Nessa perspectiva, Freire e Faundez não excluem os erros que podem ser identificados com os saberes sistematizados, e sim aqueles questionados e transformados na dúvida e na base para a negação, identificada com o ato de perguntar. Esse é o ato essencial do processo que permite elaborar o conhecimento. Nesse sentido, esses saberes ou erros são integrados no processo, o que não parece acontecer com a denominada "pedagogia nova" 5 .

\footnotetext{
${ }^{4}$ Para Freire e Faundez (1985), a pergunta é importante para a pesquisa na pós-graduação, pois "todo trabalho de tese, como todo trabalho de pesquisa, deve iniciar-se por encontrar as perguntas-chave que é preciso resolver. (p.50). (...) Parece-me, no entanto, que, para começar uma tese, o fundamental é aprender a perguntar. Uma tarefa da filosofia e do conhecimento em geral não é tanto resolver, mas perguntar, e perguntar bem (p. 51).

${ }^{5}$ Nesse sentido, a pedagogia da libertação se diferencia da Escola Nova, embora Saviani (1987) afirme que a pedagogia de Freire é uma Pedagogia Nova Popular. A polêmica entre Freire e Saviani pode ser motivo de uma ampla discussão, que ultrapassa os limites deste artigo.
} 
Outra proposta de superação da distância entre a pedagogia da resposta e a pedagogia da pergunta é trazida por Saviani, ao ser mais explícito no que se refere à manutenção da diferença entre ensino e pesquisa e, consequentemente, entre discurso científico e discurso didático, entre o método de pesquisa (que produz conhecimento) e o método de exposição (que transmite os resultados), entre as perguntas e as respostas (SAVIANI, 1987). Embora exija a distinção formal entre as duas pedagogias, assim como afirma Marx (1968), ao se referir aos métodos de pesquisa e exposição, Saviani afirma que eles devem ser integrados como momentos de um mesmo processo.

Nas teses da curvatura da vara, Saviani (1986) explicita a distinção entre ensino voltado para o domínio dos saberes sistematizados e a pesquisa voltada para a elaboração de novos conhecimentos, defende a sua articulação na necessidade de domínio dos conhecimentos disponíveis para assegurar a incursão no desconhecido. De igual forma, quando confronta a pedagogia tradicional (pedagogia da essência) e a pedagogia nova (pedagogia da existência), à semelhança de Suchodolski (1978), propõe integrá-las dialeticamente "para além das pedagogias da essência e da existência" (SAVIANI, 1987, p. 66).

Essa superação tem um significado histórico, já que se refere à passagem de uma pedagogia igualitária (tradicional) para uma pedagogia da diferença (nova), com as consequências políticas da justificação dos privilégios. Ambas as pedagogias são idealistas e ingênuas por pensarem a educação como redentora da humanidade e por faltar nelas a perspectiva historicizadora e o reconhecimento dos condicionantes sociais da educação. A igualdade formal defendida pela pedagogia da essência precisa ser transformada na igualdade real, dependendo das condições concretas e históricas da existência dos homens (pedagogia da existência) e dos conteúdos formais, fixos, sistematizados e abstratos, que precisam ser transformados em conteúdos reais, dinâmicos, concretos, vivos e atualizados, de acordo com a dinâmica e problemas atuais da sociedade. Em síntese, a proposta de uma pedagogia revolucionária para além da pedagogia nova e tradicional deve ser crítica.

A pedagogia revolucionária situa-se, pois, além das pedagogias da essência e da existência. Superaas, incorporando suas críticas recíprocas numa proposta radicalmente nova. O cerne dessa novidade radical consiste na superação da crença seja na autonomia, seja na dependência absoluta da educação em face das condições sociais vigentes. (SAVIANI, 1986, p. 69).

Os métodos de uma pedagogia revolucionária devem corresponder aos interesses populares que valorizam uma escola que funcione bem e com métodos eficazes de ensino.

Tais métodos se situam para além dos métodos tradicionais e novos, superando por incorporação as contribuições de uns e de outros. Portanto, serão métodos que estimularão a atividade e a iniciativa dos alunos sem abrir mão, porém, da iniciativa do professor; favorecerão o diálogo dos alunos entre si e com o professor, mas sem deixar de valorizar o diálogo com a cultura acumulada historicamente; levarão em conta os interesses dos alunos, os ritmos de aprendizagem e o desenvolvimento psicológico, mas sem perder de vista a sistematização lógica dos conhecimentos, sua ordenação e graduação para efeitos dos processos de transmissãoassimilação dos conteúdos cognitivos. (SAVIANI, 1986, p. 72).

Todo esse processo tem como referência a educação, tida basicamente como uma prática social. Dessa forma, o ponto de partida está na prática social dos alunos e professores, sem perder de vista os diferentes níveis de compreensão que eles têm dessa prática social (sincrética ou de síntese precária). O passo a seguir nesse processo é a problematização dessa prática. O terceiro passo consiste na apropriação dos instrumentos, tanto teóricos como práticos, para compreensão dos problemas detectados. O quarto refere-se à catarse ou incorporação de instrumentos culturais, transformando-os em elementos ativos da transformação social. O quinto passo refere-se ao ponto de chegada, que é a mesma prática social.

Através desse processo, que tem como ponto de partida e de chegada a prática social, acontece uma alteração qualitativa. A prática social não é a mesma, embora dependa das condições objetivas dos agentes sociais ativos e concretos. Daí porque a educação, ao contrário do messianismo pedagógico, não transforma direta e imediatamente a prática social; depende do grau de elevação da consciência e compreensão que os agentes ativos devem ter dessa prática, para a qual devem contribuir os processos pedagógicos, visando colocar a educação a serviço da transformação das relações sociais de produção.

Os autores acima citados têm em comum, além da apresentação de conflito entre as pedagogias das respostas (tradicionais) e as pedagogias das perguntas (novas), também a explicitação de propostas críticas que, com base nos conflitos, tendem a superá-los na medida em que as práticas pedagógicas são problematizadas, questionadas e indagadas. Sem desconhecer as diferenças de época entre Sócrates (século V a C) e Comenio (Século XVI), de Freire e Saviani (Século XX) e dos diferentes pressupostos epistemológicos, metafísicos (Sócrates), empirismo (Comenio), existencialismo cristão (Freire) e materialismo histórico (Saviani), po- 
demos retomar as suas contribuições para ampliar a discussão sobre a unidade de contrários entre saberes e conhecimento. Um desses pontos de congruência é a problematização, entendida por Sócrates como ajuda para dar luz à verdade, qualificando as perguntas (maiêutica); por Comenio, como polêmica sobre as diversas versões referentes aos objetos distantes; por Freire, como pedagogia da pergunta ou indagação do erro; e por Saviani, como um passo significativo na compreensão da educação como prática social.

Problematizar pode ser entendido como procurar o problema, buscar os conflitos que podem estar nas versões elaboradas sobre os fenômenos, na vida cotidiana e na prática social. De qualquer maneira, problematizar significa duvidar, indagar, questionar, perguntar sobre o problema. O problema se apresenta como necessidade, necessidade de problematizar o problema.

Com base no conceito da "problematização", como foi justificado acima, é possível diferenciar as pedagogias das respostas e as pedagogias das perguntas, já que as duas supõem abordagens e processos opostos e conflitantes. Entretanto, é preciso construir a unidade prática e conceitual com base no conflito entre essas pedagogias nas condições políticas e sociais críticas em que se encontra a educação. Como superar, na conjuntura atual, as ilusões e os fetiches reproduzidos na chamada sociedade do conhecimento e nas pedagogias da moda, que desconsideram os valores científicos filosóficos e culturais acumulados e o rigor dos processos da pesquisa e da produção do conhecimento? Esperamos que estas reflexões contribuam para compreender a necessidade de responder a essas questões.

\section{Conclusões}

As contradições expostas entre as pedagogias das respostas e das perguntas certamente podem ganhar graus de compreensão quando destacamos a distinção epistemológica entre as perguntas e as respostas como momentos de um mesmo processo de compreensão do mundo, da necessidade e dos problemas do gênero humano. A distinção entre trabalhar apenas com respostas ou perguntas possibilita entender as dificuldades e limites da skhola apenas como lugar do ócio e do lazer e permite a compreensão da importância da dúvida como motor da busca da verdade através do debate, da polêmica qualificada, da arte de duvidar e de perguntar, proposta pela maiêutica socrática. $\mathrm{O}$ esclarecimento sobre os conflitos postos pelas pedagogias ganha maiores graus de compreensão quando são denunciados os limites dos conteúdos impostos pelo verbalismo, são ponderados os avanços, os limi- tes do discurso polêmico e é resgatado o potencial heurístico do discurso lúdico proposto por Comenio. Essas distinções entre as pedagogias no seu trato com as formas básicas da produção e difusão do conhecimento acumulado pela humanidade (relação pergunta-resposta) poderão, certamente, ajudar no resgate da importância da problematização dos saberes científicos, acadêmicos e escolares e da necessidade de inserir a formação básica para a pesquisa e a produção do conhecimento nos cursos de pedagogia e na prática profissional dos educadores, sem recuar e negar os saberes acumulados pela humanidade.

De igual maneira, o entendimento da relação dialética entre saberes (respostas prontas) e conhecimento (relação direta entre pergunta e respostas novas) poderá ajudar na valorização das contribuições das pedagogias da pergunta, no incentivo à curiosidade e ao desenvolvimento da capacidade de duvidar e perguntar, sem precisar desprezar os saberes acumulados e os conteúdos das pedagogias das respostas, apenas por estarem associados às práticas autoritárias da educação bancária (Freire). A falta dessa distinção entre saberes e conhecimento como partes imbricadas de um mesmo processo de produção e disseminação dificulta o debate das pedagogias críticas com a denominada "escola nova" e com as pedagogias das perguntas (Saviani). A distinção entre saberes e conhecimento poderá ajudar no esclarecimento dos conflitos da denominada "sociedade do conhecimento", a qual, voltada para o mercado e o consumo de informações, saberes e respostas prontas, encontra-se longe dos processos de produção do conhecimento. Isso porque padroniza e nivela as respostas científicas junto com os outros saberes e os distancia da relação originária entre pergunta-resposta, base de todo e qualquer conhecimento (BACHELAR, 1989).

Nessa perspectiva, a formação profissional dos educadores torna-se necessariamente mais complexa, já que precisa de respostas válidas para os problemas e necessidades da sua prática social e para a realização de seus compromissos históricos no sentido de potencializar a sociedade do futuro. Novas capacidades precisam ser desenvolvidas para articular o domínio dos saberes sistematizados e o potencial criativo da pesquisa científica, dos instrumentais técnicos e teóricos necessários para a produção de novas respostas para as necessidades históricas da sociedade na fase atual de profundos processos de transformação. Essa formação profissional exige a articulação da formação teórica sólida, com base no conhecimento científico, e a formação básica para a pesquisa e a produção do conhecimento em educação.

No contexto do conflito da expansão quantitativa da escolaridade e os desafios da qualidade da 
educação, certamente a retomada dessas questões essenciais da pedagogia podem contribuir para a construção de uma formação qualificada dos educadores nas brechas que as novas diretrizes curriculares abrem para a sólida fundamentação teórica, a capacidade de se apropriar dos saberes científicos acumulados pela humanidade e a necessidade da formação básica para a produção de novas respostas para os desafios da educação. Esse educador fará a diferença na sua prática social transformadora.

\section{Referências}

ANPED. Pronunciamento conjunto das entidades da área da educação em relação às diretrizes curriculares nacionais para o curso de graduação em Pedagogia. Educação e Sociedade, Campinas, v. 27, n. 97, p. 1361-1363, set./ dez. 2006.

BRASIL. Conselho Nacional de Educação. Resolução $\mathbf{n}$. 1, de 15 de maio de 2006. (Aprova as Diretrizes Curriculares Nacionais do Curso de Pedagogia).

BACHELARD, G. Epistemologia. Barcelona: Anagrama, 1989.

CHEPTULIN, A. Dialética materialista. São Paulo: AlfaOmega, 1982.

COMENIO, J. A. Didáctica Magna. Lisboa: Fundação Calauste Gulbenkian, 1985.

DUARTE, N. Sociedade do conhecimento ou Sociedade das ilusões? Campinas, SP: Autores Associados, 2003.

FREIRE, P.; FAUNDEZ, A. Por uma pedagogia da pergunta. Rio de Janeiro: Paz e Terra, 1985.

KUENZER, A. Z.; RODRIGUES, M. F. As Diretrizes Curriculares para o Curso de Pedagogia: uma expressão da epistemologia da prática? In: SILVA, A. M. M; MACHADO, L. B.; MELO, M. M; AGUIAR, M. (Orgs.). Novas subjetividades, currículo, docência e questões pedagógicas na perspectivas de inclusão social. Encontro Nacional de Didática e Prática de Ensino. XII ENDIPE. Recife: Edições Bagaço, 2006, p. 185-212.

MARX, K. O capital. v. 1. Rio de Janeiro: Civilização Brasileira, 1968.

SÁNCHEZ GAMBOA, S. Comenio y la actual crisis de la didáctica. Momento Pedagógico, México, Universidade Pedagógica Nacional, p. 6-11, abr./jun. 1992.

Epistemologia da Educação Física: as interrelações necessárias. Maceió: EDUFAL, 2007.

SAVIANI, D. Escola e democracia. São Paulo: Autores Associados, 1986.

Ensino público e algumas falas sobre Universidade. São Paulo: Cortez/Autores Associados, 1987.

Pedagogia: o espaço da educação na universidade. Cadernos de Pesquisa, São Paulo, v. 37, n. 130, p. 99-134, jan./abr. 2007.
SCHEIBE, L. Diretrizes curriculares para o curso de pedagogia: trajetória longa e inconclusa. Cadernos de Pesquisa, v. 37, n. 130, p. 43-62, jan./abr. 2007.

SUCHODOLSKI, B. A pedagogia e as grandes correntes filosóficas: pedagogia da essência e da existência. Lisboa: Livros Horizonte, 1978.

Recebido em 11/12/2008

Reformulado em 25/03/2009

Aceito em 2/04/2009. 